\title{
EXTENDING ONLINE AND BLENDED LEARNING TO CORPORATIONS IN THE NEW YORK METROPOLITAN REGION
}

\author{
Robert Ubell \\ Dean, School of Professional Education \\ Stevens Institute of Technology
}

\section{INTRODUCTION}

WebCampus.Stevens, the online graduate education and corporate training unit of Stevens Institute of Technology, delivers one of the largest and most effective ALN and blended programs of any college or university in the New York metropolitan region. Under a newly awarded Sloan Foundation grant [1], the school is extending its engineering and management programs to area corporations, supporting local telecommunications, pharmaceutical/life sciences, media, finance and other key industries. Stevens provides local employees of Fortune 500 and other companies access to high-quality online advanced technical and managerial skills, preparing them for success in global competition.

Established in 1870, Stevens offers baccalaureate, masters and doctoral degrees in engineering, science, computer science, management and technology management, as well as a baccalaureate in the humanities and liberal arts, and in business and technology. The university enrolls about 1,800 undergraduates and 2,600 graduate students. It is one of the oldest and most respected engineering and management schools in the nation with a long tradition of meeting the technical and managerial needs of local industry.

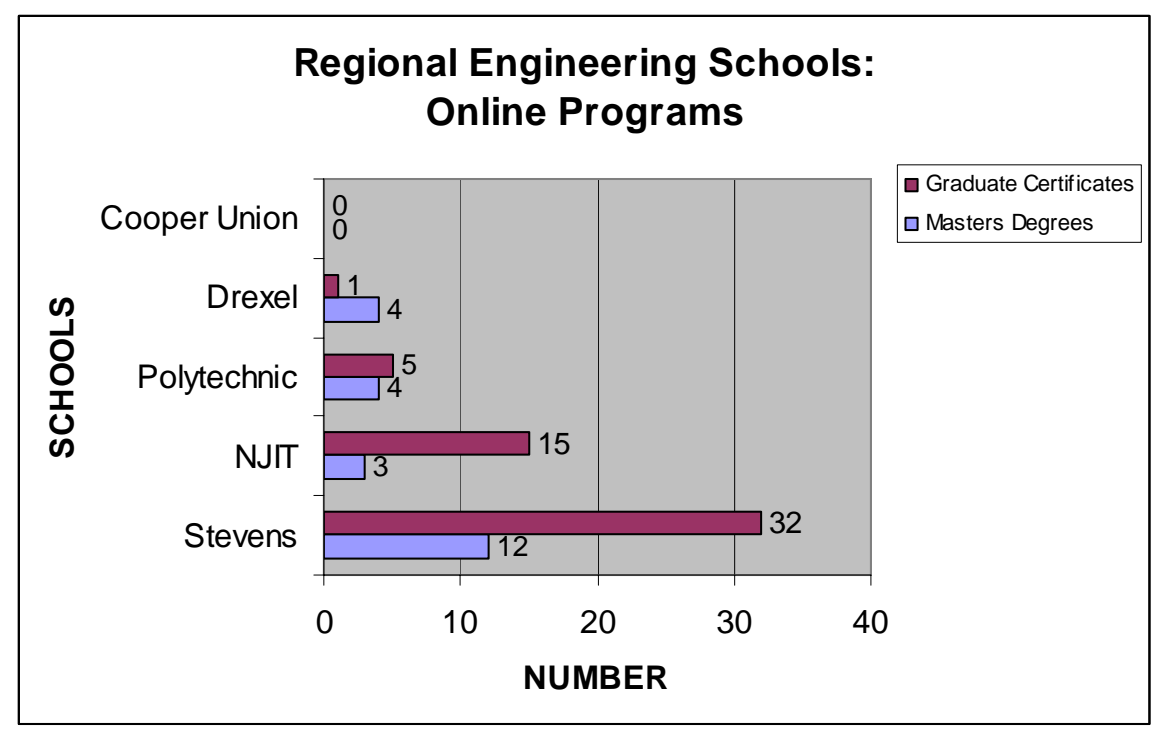

Table 1. Data Compiled from the Schools' Websites. Comprehensive Universities in the Region, Such as Columbia, CUNY, Rutgers, and Pace are Not Included. 
When compared with the four other regional engineering schools-New Jersey Institute of Technology, Polytechnic University, Drexel University, and Cooper Union-Stevens' online learning effort is by far the most robust (see chart above). The school offers more online masters degrees and graduate certificates than all four combined. It is also the only regional engineering school with an online MBA [2].

\section{LOCAL ENROLLMENT}

The table for fiscal year 2004-05 that follows compares the number of graduate enrollments by geographic regions throughout the US. The data confirm the strength of WebCampus' local penetration. Approximately $84 \%$ of graduate enrollments are from New Jersey, New York, Pennsylvania, and Connecticut.

As the table below shows, while Stevens has an excellent record of attracting students at a distance (with enrollments over the five-year period from 44 US states and 42 countries abroad), the number of students drawn from the local region only is significant. The next two maps confirm this local impact.

\begin{tabular}{|lll}
\hline Local States & Number & Percent \\
\hline New Jersey & 1,486 & \\
New York & 198 & \\
Pennsylvania & 62 & \\
Connecticut & 7 & $\mathbf{8 4 \%}$ \\
\hline Total Local & $\mathbf{1 , 7 5 3}$ & $\mathbf{1 6 \%}$ \\
\hline Total Distant & $\mathbf{3 3 5}$ & $\mathbf{1 0 0 \%}$ \\
\hline Total Combined & $\mathbf{2 , 0 8 8}$ &
\end{tabular}

Table 2. Local vs. Distant WebCampus Enrollments (Calendar Year 2006). Excludes Undergraduates Enrolled in Graduate Online Courses.

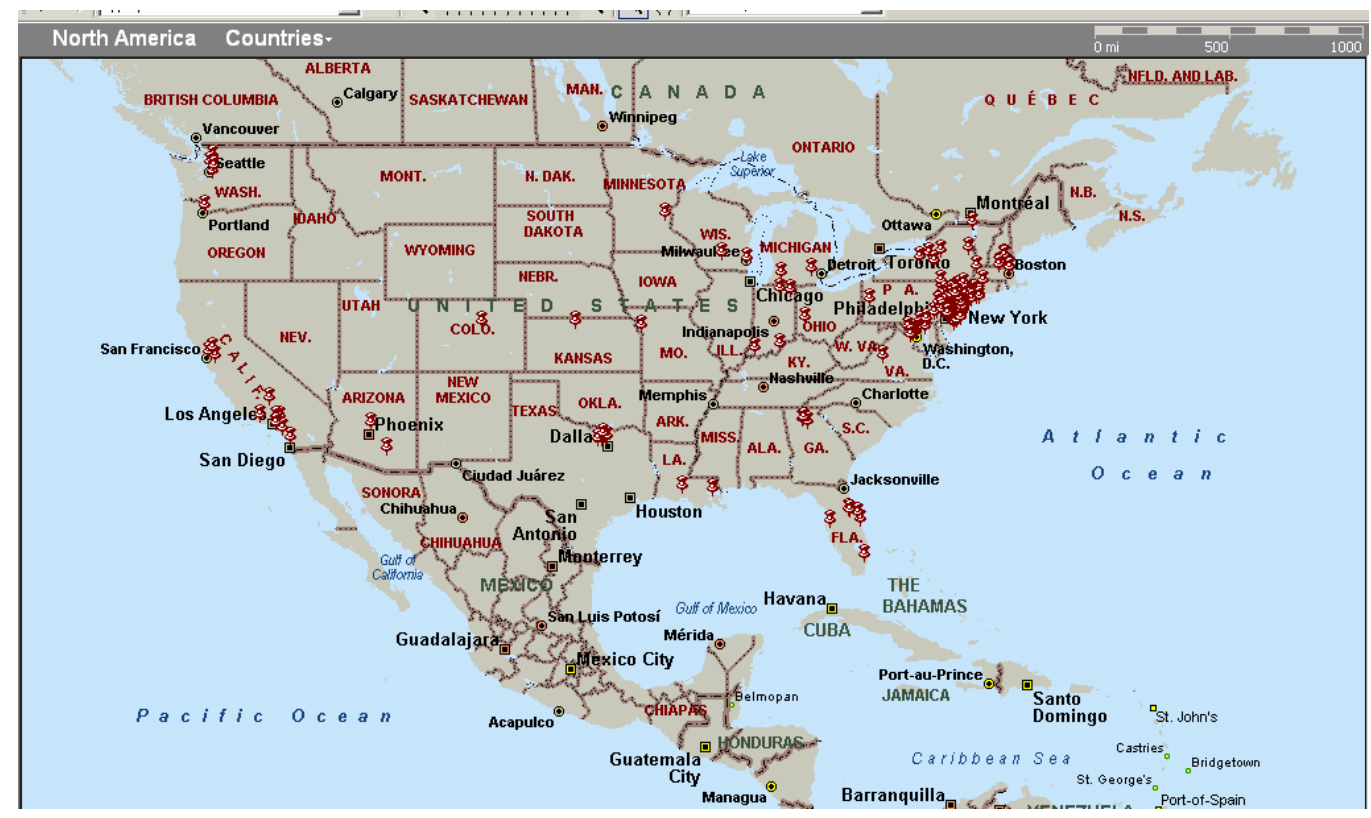

Map 1: Distribution of Local vs. National Enrollment Pushpin Images Represent Locations of Webcampus Students. 


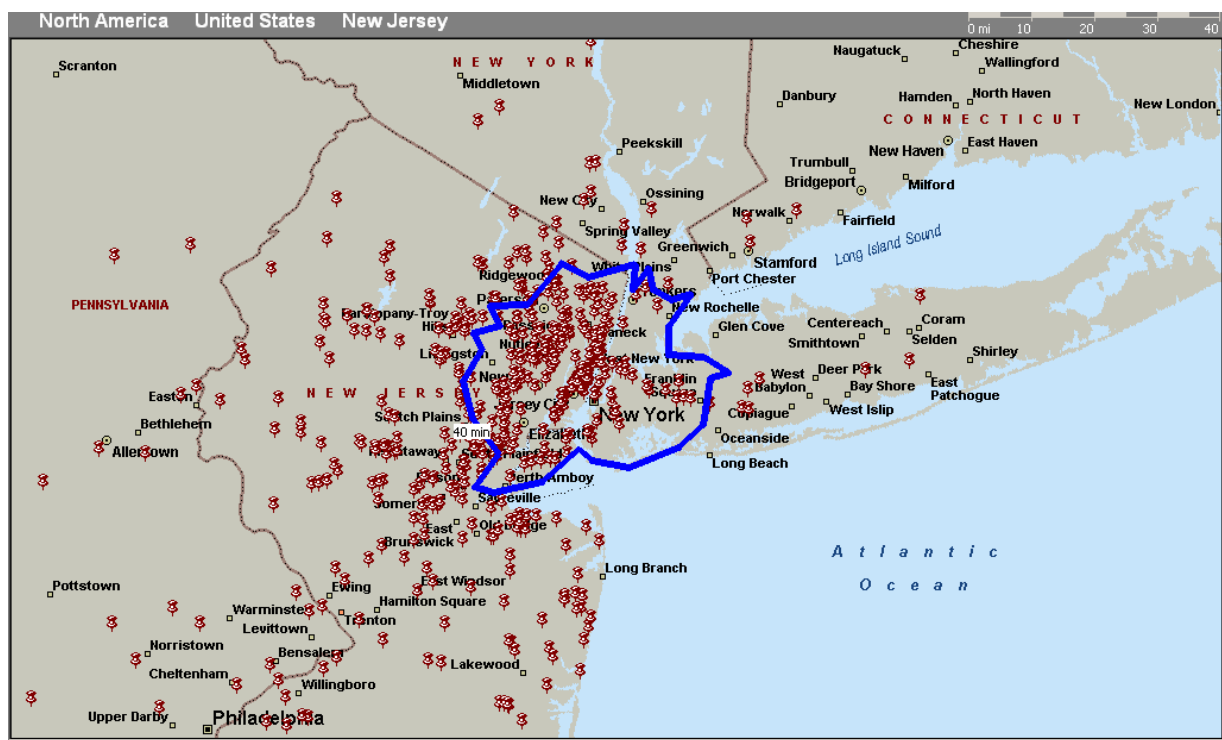

Map 2: Local Enrollment D

Pushpin Images Represent Locations of Webcampus Students. Blue Line Indicates Outer Circumference of Convenient Commuting Distance From Stevens' Hoboken, NJ Campus.

Winner of the 2003 Sloan-C award for Institution-wide Teaching and Learning Programs, WebCampus has also been awarded the 2005 US Distance Learning Association's “ $21^{\text {st }}$ Century Best Practices” prize as the best online graduate school. The school began offering online graduate courses in 2000 with full accreditation granted by the Middle States Commission on Higher Education two years afterwards.

Today, WebCampus offers a dozen masters degrees (including an MBA in Technology Management) and more than 30 graduate certificate programs in science, technology and technical management. Teaming and collaborative learning are among the key pedagogical requirements of WebCampus online instruction [3]. These elements parallel the needs of global corporations for technical and managerial personnel to perform effectively in highly competitive environments [4].

\section{ASYNCHRONOUS DELIVERY}

WebCampus employs WebCT as its online course management system, consistently upgrading it for easier navigation. Online students have convenient access to every university service available on campus - online application, registration, advising, access to faculty, bookstore, library access, e-mail, and technical support.

Graduate programs fall under the university's three schools-Sciences and Arts (ISSA), Technology Management (STM), and Engineering (SOE). Combined, the three schools offer 708 graduate courses, 308 of which (or $43.5 \%$ ) have been migrated to online and blended delivery (see chart below). The school plans eventually to deliver all its graduate courses on campus and online, a target that no other local or even national school has yet accomplished. 


\begin{tabular}{lllllll} 
School & \multicolumn{2}{l}{ Courses Developed } & \multicolumn{2}{l}{$\begin{array}{l}\text { Courses } \\
\text { To Be Developed }\end{array}$} & \multicolumn{2}{l}{ Total Courses } \\
\hline & Number & Percentage & Number & Percentage & Number & Percentage \\
\cline { 2 - 7 } Science (ISSA) & 63 & $36.6 \%$ & 109 & $63.4 \%$ & 172 & $100 \%$ \\
Management (STM) & 92 & $79.3 \%$ & 24 & $20.7 \%$ & 116 & $100 \%$ \\
Engineering (SOE) & 153 & $36.4 \%$ & 267 & $63.6 \%$ & 420 & $100 \%$ \\
\hline TOTAL & $\mathbf{3 0 8}$ & $\mathbf{4 3 . 5} \%$ & $\mathbf{4 0 0}$ & $\mathbf{5 6 . 5} \%$ & $\mathbf{7 0 8}$ & $\mathbf{1 0 0 \%}$ \\
\hline
\end{tabular}

Table 3. Migration of Stevens Graduate Courses to Online Delivery

\section{SYNCHRONOUS DELIVERY}

In 2005, WebCampus introduced synchronous technology to enhance student learning and to permit the introduction of more blended courses. Using Interwise, a voice-over-IP web-conferencing system, instructors conduct real-time and recorded lectures. Interwise enables students to deliver online presentations to others in their virtual class and engage in online team projects. About $15 \%$ of WebCampus online courses now offer Interwise as an option. The school plans to expand its use to all WebCampus courses in the next few years.

Synchronous learning tools enhance online delivery, particularly for local students. Those far from campus, especially in different time zones, are less likely to engage in live synchronous sessions. Interwise opens additional blending options, giving instructors alternative delivery methods, including ALN, conventional classroom instruction, and now online synchronous education.

\section{BLENDED LEARNING}

Stevens' System Design and Operational Effectiveness (SDOE) program offers blended delivery consisting of two- to three-day, face-to-face sessions extended over a number of weeks online. Launched three years ago, it is the most robust and fastest-growing of Stevens' hybrid programs. SDOE delivers courses to a number of local institutions, including the Federal Aeronautics Administration (FAA), IBM, ITT, Lockheed-Martin, and Northrop Grumman, among others. SDOE partners with about a dozen corporations and government agencies, delivering 20 traditional face-to-face courses with 12 taught online. A parallel blended program in project management began in the spring of 2006 at FAA in Atlantic City.

The school encourages local students to earn their graduate degrees in hybrid mode [5]. Taking some of their courses online and others on campus, students who live within commuting distance can earn their degrees more rapidly by traveling to campus for some of their courses while taking others online from home or elsewhere. Stevens plans to offer blended learning options for most graduate programs to permit wider acceptance at local corporations seeking alternative, flexible education and training options.

\section{LOCAL CORPORATE STRATEGY}

Stevens has a long and solid tradition of offering graduate programs directly to local corporate and government clients. Stevens offered online education to regional corporate clients immediately after WebCampus was launched. Today, the school provides more than 50 industry and government organizations with onsite, online and blended education. The school's most important regional clients are Citigroup, Consolidated Edison Company of N.Y., Inc., Honeywell, Johnson \& Johnson, LockheedMartin, Picatinny Arsenal, and Verizon Communications. The aim now is to play an even greater role in 
supporting these key regional industries—pharmaceutical/life sciences, media and publishing, banking and finance, telecommunications and cable, energy, and defense.

\section{ONLINE CORPORATE TRAINING}

Under the School's newly introduced School of Professional Education, Stevens has embarked on a regional effort to deliver corporate training to Fortune 500 and other companies. Working closely with company learning officers, Stevens' faculty and staff modularize graduate courses, abbreviating and customizing them for more efficient and effective training. Upon completing certain courses, Stevens provides employees with CEU and PDU credits, especially those in project management.

In mid-2006, Stevens completed an eight-week ALN course, incorporating Interwise synchronous elements, to Consolidated Edison's senior management. Following its successful implementation, the company agreed to offer it to other ConEd personnel. Hybrid and online corporate training programs are either in progress or in discussions with learning officers at local divisions of FAA, Ethicon, IBM, and others. Stevens' SDOE program also provides partially online corporate training regionally to IBM, US Army and Navy, and Lockheed-Martin, among others.

The extension of the school's online and hybrid learning capabilities into the corporate training marketplace is a natural outgrowth of Stevens' systematic effort to collaborate with local industry, not only in research and education, but in corporate training as well. These pilot programs in delivering ALNstyle training to company personnel are among the very first anywhere.

In order to accomplish its ambitious goals, Stevens' staff enters into contractual arrangements with training officials, heads of functional groups, or human-resources executives at local companies. Faculty and staff visit local corporate executives to negotiate these and other options:

- Posting announcements of WebCampus online programs on corporate education and training websites

- Providing tuition discounts for online and blended learning employees

- Establishing WebCampus as a "preferred educational provider"

- Sending e-mail alerts to employees about Stevens online and blended programs

- Announcing WebCampus programs in corporate online and print newsletters

- Distributing Stevens marketing and adverting materials to employees

- Attending local corporate education fairs

- Arranging exclusive online and blended learning vendor agreements

- Customizing corporate training to meet company objectives

WebCampus has grown from merely 23 enrollments in its first semester five years ago to more than 10,000 cumulative enrollments in the fall of 2006. The chart below illustrates dramatic annual increases year to year. For the last completed academic year (2004-2005), WebCampus total online graduate enrollment reached 1,832, representing $14 \%$ of the school's graduate enrollment, ahead of US higher education's national average of $11 \%$ for online courses (as of fall 2002). 


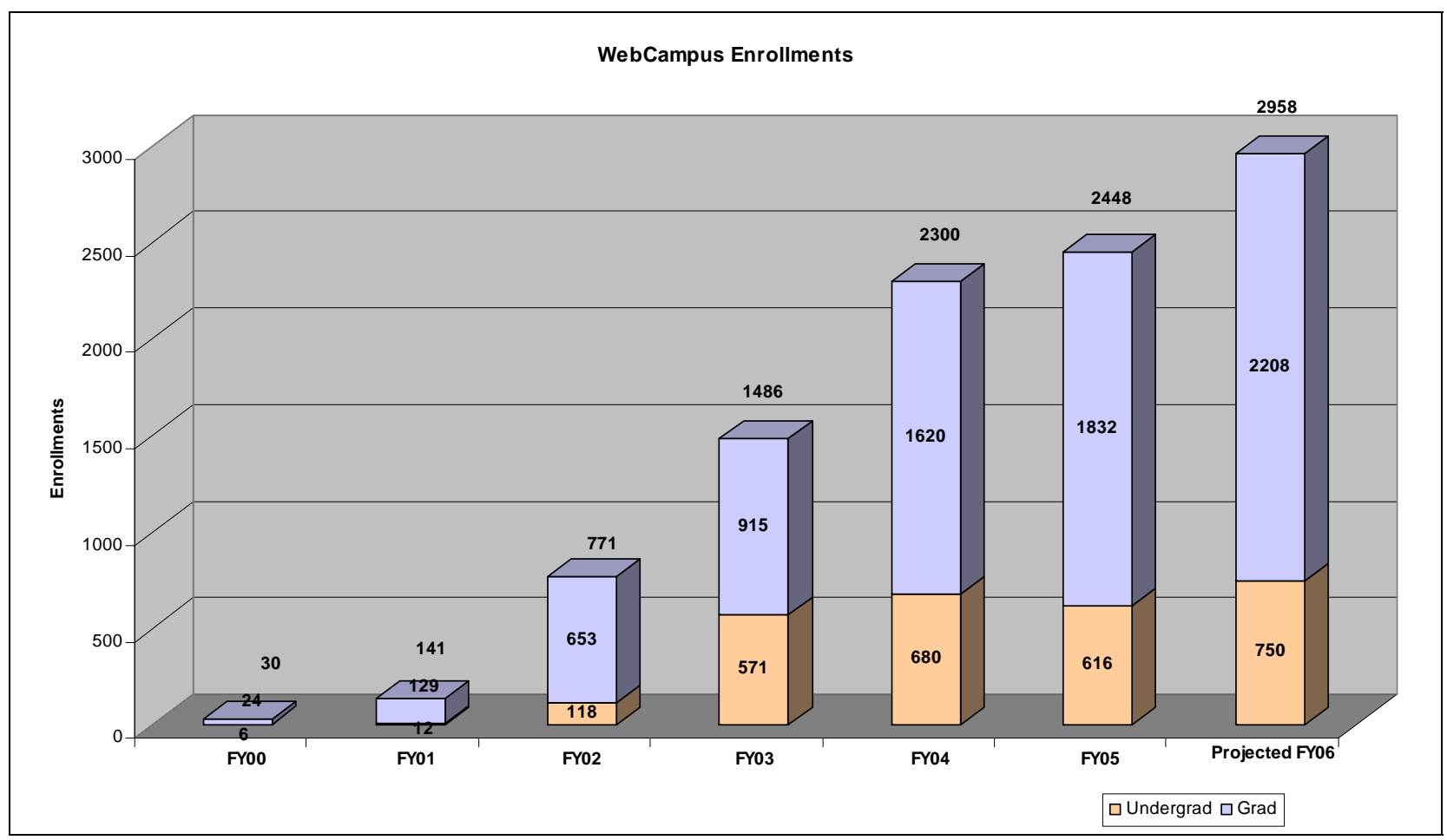

Table 4. Web Campus Enrollments

\section{ONLINE AND BLENDED FACULTY}

Of approximately 328 Stevens faculty, 105 teach WebCampus courses, representing about 32\% of the school's faculty. About two-thirds are full-time, another third, part-time. The same faculty who teach on campus also teach online with the same curriculum as in conventional classes. Oversight of online curriculum is in the hands of the school's Graduate School Committee, which is equally responsible for oncampus as well as online and blended instruction. Nearly all WebCampus faculty who provide instruction return afterwards to teach online again.

Given Stevens' accomplished record of providing local industry with a variety of educational and training options - on campus, on-site, online, and blended delivery-the school anticipates that tri-state area companies will join Stevens in partnerships to offer their employees a full range of technical and management programs to allow them to compete nationally and, perhaps more importantly, globally.

\section{ABOUT THE AUTHOR}

Robert Ubell is Dean of the School of Professional Education at WebCampus Stevens Institute of Technology. He has held a number of positions in publishing, e-commerce, and education. He was vicepresident and editor-in-chief of Plenum Publishing Corporation, editor of The New York Academy of Sciences monthly, The Sciences, and American publisher of Nature. He was also founding publisher of Nature Biotechnology. He has held senior posts as an Internet executive-president of BioMedNet and executive vice president for new media at Marcel Dekker. Ubell was head of his own consulting firm, Robert Ubell Associates, representing such clients as Elsevier, Harcourt, Wiley, and McGraw-Hill, among dozens of others, including various nonprofit groups, such as the American Cancer Society and the American Institute of Physics. Ubell has consulted for numerous corporations and nonprofit groups, including the National Academy of Sciences, National Academy of Engineering, IBM, Xerox, Lotus, and 
MIT, Cambridge, and Columbia University presses.

\section{REFERENCES}

1. Alfred P. Sloan Foundation. New York Tri-State Area Corporate Online Engineering and Management Grant. Awarded June 2006.

2. Skaare, R. In Line with Online Success: The Stevens Institute of Technology/WebCampus Stevens. Corporate University Xchange, 2006. http://www.corpu.com/news/writings/2006-stevens.asp.

3. Volchok, E. Building Better Virtual Teams. eLearn Magazine 37(1): 2006. http://www.elearnmag.org/subpage.cfm?section=case studies\&article=37-1.

4. Ubell, R. Engineers Turn to eLearning. IEEE Spectrum, October 2000.

5. In China, Stevens offers several graduate programs in hybrid form, with a third of the courses delivered online, another third by Stevens' instructors who travel to Beijing, and yet another third by Chinese faculty from local partner schools. Available online at http://www.stevens.edu /gradadmissions/china.html for further details. See also:

a. Bourne, J. R. The China Trade: An Online Education Strategy at Stevens Institute. Sloan-C View 5(9): 2006. http://webcampus.stevens.edu/ChinaTrade_Sloan.html.

b. Lorenzo, G. Stevens Institute of Technology Forms Partnerships with Four Chinese Institutions to Offer Hybrid Graduate Degree Programs. Educational Pathways, September 2006. http://www.edpath.com/stevens.htm.

c. Lui, J. L. Management American Style: A US University Reaches Western Business Ways to Chinese Students. IEEE Spectrum, June 2005. http://ieeexplore.ieee.org/iel5/6/ 30951/01437031.pdf. 